\title{
A decrease in cesarean sections and labor inductions among Swedish women by awareness of fetal movements with the Mindfetalness method
}

\author{
Anna Akselsson ${ }^{1,2^{*}}$, Helena Lindgren ${ }^{2}$, Viktor Skokic $^{3}$ and Ingela Rådestad ${ }^{1}$
}

\begin{abstract}
Background: Maternal perception of decreased fetal movements is commonly used to assess fetal well-being. However, there are different opinions on whether healthcare professionals should encourage maternal observation of fetal movements, as researchers claim that raising awareness increases unnecessary interventions, without improving perinatal health. We aimed to investigate whether cesarean sections and labor induction increase by raising women's awareness of fetal movements through Mindfetalness. Further, we aimed to study perinatal health after implementing Mindfetalness in maternity care.

Methods: In a cluster randomized controlled trial, 67 maternity clinics were allocated to Mindfetalness or routine care. In the Mindfetalness group, midwives distributed a leaflet telling the women to focus on the character, strength and frequency of the fetal movements without counting each movement. The instruction was to do so for 15 min daily when the fetus was awake, from gestational week 28 until birth. In this sub-group analysis, we targeted women born in Sweden giving birth from 32 weeks' gestation. We applied the intention-to-treat principle.

Results: The Mindfetalness group included 13,029 women and the Routine-care group 13,456 women. Women randomized to Mindfetalness had less cesarean sections (18.4\% vs. 20.0\%, RR 0.92, Cl 0.87-0.97) and labor inductions (19.2\% vs. 20.3\%, RR 0.95, Cl 0.90-0.99) compared to the women in the Routine-care group. Less babies were born small for gestational age (8.5\% vs. 9.3\%, RR 0.91, Cl 0.85-0.99) in the Mindfetalness group. Women in the Mindfetalness group contacted healthcare due to decreased fetal movements to a higher extent than women in the Routine care group (7.8\% vs. 4.3\%, RR 1.79, Cl 1.62-1.97). The differences remain after adjustment for potential confounders.
\end{abstract}

Conclusions: Raising awareness about fetal movements through Mindfetalness decreased the rate of cesarean sections, labor inductions and small-for-gestational age babies.

Trial registration: ClinicalTrials.gov (NCT02865759). Registered 12 August 2016, www.clinicaltrials.gov.

\footnotetext{
* Correspondence: anna.akselsson@shh.se

'Sophiahemmet University, Stockholm, Sweden

2Department of Women and Children's Health, Karolinska Institutet, Stockholm, Sweden

Full list of author information is available at the end of the article
}

C C The Author(s). 2020 Open Access This article is licensed under a Creative Commons Attribution 4.0 International License, which permits use, sharing, adaptation, distribution and reproduction in any medium or format, as long as you give appropriate credit to the original author(s) and the source, provide a link to the Creative Commons licence, and indicate if changes were made. The images or other third party material in this article are included in the article's Creative Commons licence, unless indicated otherwise in a credit line to the material. If material is not included in the article's Creative Commons licence and your intended use is not permitted by statutory regulation or exceeds the permitted use, you will need to obtain permission directly from the copyright holder. To view a copy of this licence, visit http://creativecommons.org/licenses/by/4.0/. The Creative Commons Public Domain Dedication waiver (http://creativecommons.org/publicdomain/zero/1.0/) applies to the data made available in this article, unless otherwise stated in a credit line to the data. 


\section{Background}

As a way to prevent stillbirths and other adverse birth outcomes, researchers in the field suggest that pregnant women's awareness of fetal movements is an important tool [1]. However, Walker and Thornton offer a different opinion, claiming that informing pregnant women about fetal movements is harmful and increases the occurrence of unnecessary interventions [2]. Their critique is based on a randomized controlled trial (AFFIRM) [3], where an intervention that included providing information about fetal movements to the pregnant women, and introducing new guidelines to the clinics, increased the number of labor inductions and cesarean sections. Further, the number of babies in need of neonatal care for more than $48 \mathrm{~h}$ was also higher in the intervention group.

In Sweden, midwives are responsible for providing maternal care, and almost all pregnant women attend regularly at no cost. Additionally, if necessary, the women are able to have an extra appointment with an obstetrician at a maternity clinic or, if urgent, at a birth clinic [4]. In the capital, Stockholm, $62 \%$ of women who attend maternity care are born in Sweden [5]. These women are at lower risk of negative birth outcomes compared to women born in other countries who have migrated to Sweden [6]. In a cluster-randomized controlled trial, we allocated women to either receive or not receive information about Mindfetalness, a method designed to systematically observe fetal movements. A leaflet including information about fetal movements and instructions on how to practice Mindfetalness were distributed to the women by their midwives. We have previously reported the main analyses for the whole group of women [7]. Our data, as well as our clinical experience, indicate a large number of modifying and possible confounding factors, with many being associated with country of birth. These include knowledge level, cultural attitudes and language comprehension. Here we want to focus on the possible adverse effects of increasing the women's awareness of fetal movements. To increase validity and the understanding of generalizability, we restricted the analysis to native Swedish-born women. The aim was to investigate whether cesarean section and labor induction increase by raising women's awareness of fetal movements through Mindfetalness.

\section{Methods}

The study base constitutes pregnant women living in Stockholm, born in Sweden, and who gave birth from 32 weeks' gestation. The women are drawn from a clusterrandomized controlled trial in which pregnant women, registered at a maternity clinic in Stockholm, Sweden, were randomized to either be informed by their midwife about Mindfetalness or to receive routine care. More information about the method and the randomization process can be found in previous papers $[7,8]$. The randomization was carried out via the 78 maternity clinics in the area. Five clinics were excluded because of the small number of women registered annually $(<50)$ and, additionally, six specialized maternity clinics were excluded. Before the randomization, the maternity clinics were divided into two groups based on the socio-demographics of the area in which the clinics were located; high income area, and nonhigh-income area. The clinics were further divided based on the number of women registered at each clinic in 2015, the year before recruitment started: small $(n<500)$, medium $(n=500-1000)$ or large $(n>1000)$. Eventually, 33 maternity clinics were randomized to Mindfetalness and 34 maternity clinics to routine care. After the randomization, due to organizational amalgamation, three maternity clinics merged into one clinic and two maternity clinics merged into one clinic, which resulted in a total of 31 maternity clinics in the Routine-care group.

The intervention procedure included the preparation and distribution of a leaflet about fetal movements and the Mindfetalness method to be given to women with singleton pregnancies, registered at a clinic randomized to Mindfetalness (supplementary material). When the leaflets were distributed to the maternity clinics, a lecture about fetal movements and Mindfetalness was delivered to the midwives working at the clinics. A website (www.mindfetalness.com) providing the same information as found in the printed leaflet was made available and open for anyone to access.

The midwives were instructed to hand out the leaflet at a routine visit in gestational week $24+0$, telling the women to start practicing Mindfetalness from gestational week $28+0$ and continuing until birth. The women were informed that it was optional for them to use the method and that the quality of maternity care would not be affected by their choice of whether to practice Mindfetalness. Those who wanted to try Mindfetalness were instructed to lie down on their left side for 15 min per day when their unborn baby was awake and to monitor the character, strength and frequency of the fetal movements but not to count each movement. Furthermore, they were asked to trust their intuition and seek care if they felt that the fetal movement pattern had changed, if the movements were weaker, or if the frequency had decreased. All maternity clinics (Mindfetalness clinics and clinics randomized to routine care) continued with standard care, i.e., the midwives provided information (oral not written) about fetal movements in accordance with the guidelines from the Swedish National Board of Health and Welfare [9]; "Healthcare should provide information about fetal movements to all pregnant women in connection with the routine visit to maternal health care offered around 24 weeks' gestation." The recommendation is also that "Healthcare 
should give advice on contacting care again in the event of a renewed experience of decreased fetal movements." In the leaflet provided to the intervention group, additional information was given, which included, for example, daily systematic observation of fetal movements through the Mindfetalness method, and to focus upon "The intensity of the movements, the way in which the baby moves and how much the baby moves".

All pregnant women registered at any one of the $33 \mathrm{ma}-$ ternal clinics between 1 November 2016 and 31 January 2018 were included in the analysis. We calculated that, for a training period of at least 4 weeks for the pregnant women using the method, we required a start date at 28 weeks' gestation and therefore only included women who had given birth from 32 weeks' gestation in the analysis (thus having completed 4 weeks of Mindfetalness). The observation period was specific to each woman and newborn. We used intention-to-treat analysis. The primary endpoint was labor induction and cesarean section. Secondary endpoints were an Apgar score of zero to six (with stillbirth counting as zero) in the newborn, transfer to neonatal intensive care unit (NICU), small for gestational age, labor from gestation $41+6$, preterm delivery and "contacting health care due to decreased fetal movements". The latter was based on the diagnostic coding according to ICD-10 [10] "Examination of decreased fetal movements" (AM041), where no signs of a compromised fetus and no intervention is suggested.

All information was reported to a population-based quality register as part of routine care, regardless of the study [11]. The planning of the study includes two pilot studies $[12,13]$ and the study is registered with www. ClinicalTrials.gov, number NCT02865759. The study adheres to CONSORT guidelines. Ethics approval was obtained from the The Regional Ethics committee in Stockholm, Sweden (Dnr 2015/2105-31/1).

\section{Statistical analysis}

This is a subgroup analysis of data relating to pregnant women born in Sweden drawn from a large randomized trial $[7,8]$. Only register-based data were used. As a metric for association, we calculated percentage ratios. We employed log-binomial regression models to adjust the ratio for possible confounding factors and to calculate $95 \%$ confidence intervals. Possible confounding factors comprise age, education level, parity, previous stillbirth, tobacco use at registration, body mass index, assisted reproduction, and maternal diseases. For the analyses, we used statistical program $\mathrm{R}$ (version 3.2.4).

\section{Results}

After randomization, one maternity clinic allocated to the intervention declined participation before the study started, but, due to the intention-to-treat design, this maternity clinic was included in the intervention group when analyzing. Approximately 15,500 leaflets were handed out by the midwives during the recruitment period. We received data from 39,865 women with singleton pregnancies who gave birth from gestational week $32+0$. The Mindfetalness group consisted of a total of 19, 639 and, of those, 13,029 were born in Sweden. The corresponding figures for the routine care group were 20,226 and, of those, 13,456 were born in Sweden.

The characteristics for the Mindfetalness group and Routine-care group are displayed in Table 1. The Mindfetalness group included fewer women of advanced age ( $\geq 35$ years) $(27.4 \%$ versus $30.6 \%)$, and more with previous stillbirths $(0.5 \%$ versus $0.3 \%)$ and tobacco use at registration (3.8\% versus $2.9 \%)$. The amount of women of normal weight was the same in both groups, but more women had been treated for mental illness in the Mindfetalness group (7.4\% versus 5.6\%).

As shown in Table 2 and Fig. 1, Swedish women randomized to Mindfetalness had less cesarean sections (18.4\% versus $20.0 \%$, RR $0.92,0.87-0.97$ ) and labor inductions (19.2\% versus 20.3\%, RR 0.95, CI 0.90-0.99). Further, they started their labor spontaneously to a higher extent $(70.9 \%$ versus $68.8 \%$, RR 1.03 , CI $1.01-$ 1.05). Fewer women in the Mindfetalness group gave birth after 42 weeks' gestation (5.3\% versus $6.0 \%$, RR 0.88 , CI $0.80-0.97$ ) and less babies were born small for gestational age (below the 10th centile; $8.5 \%$ versus $9.3 \%$, RR 0.91, CI 0.85-0.99). The percentage of babies in need of transfer to neonatal care was lower in the Mindfetalness group, but the difference from the Routine-care group was not statistically significant $(6.4 \%$ versus $6.8 \%$, RR 0.94, CI 0.86-1.03). Women in the Mindfetalness group contacted healthcare due to decreased fetal movements to a higher extent than women in the Routine care group (7.8\% versus $4.3 \%$, RR 1.79 , CI 1.62-1.97) (Table 3). The statistically significant differences between the two groups remained after adjustment for age, education, body mass index, previous stillborn child, tobacco use at registration, and treatment for mental illness (calculated one single variable at a time) (Table 3).

\section{Discussion}

This analysis of Swedish-born women in a populationbased prospective trial using cluster randomization showed no indications of harm when midwives encouraged awareness of fetal movements. On the contrary, by raising awareness through Mindfetalness, labor induction and cesarean sections decreased and, further, the number of women having a small-for-gestational-age baby also decreased.

Reflecting the debate in Scandinavia, an associate editor of Acta Obstetricia et Gynecologica Scandinavica recently promoted a strategy in Sweden of not encouraging women to pay attention to their unborn baby's movements [14]. 
Table 1 Characteristics of women born in Sweden; 13,029 women registered at a maternity clinic randomized to Mindfetalness and 13,456 women registered at a maternity clinic randomized to routine care

\begin{tabular}{|c|c|c|}
\hline & $\begin{array}{l}\text { Mindfetalness } \\
n(\%)\end{array}$ & $\begin{array}{l}\text { Routine care } \\
n(\%)\end{array}$ \\
\hline \multicolumn{3}{|l|}{$\mathrm{Age}^{\mathrm{a}}$} \\
\hline$\leq 24$ & $832(6.4)$ & $694(5.2)$ \\
\hline $25-29$ & $3429(26.3)$ & $3314(24.6)$ \\
\hline $30-34$ & $5194(39.9)$ & 5331 (39.6) \\
\hline$\geq 35$ & $3574(27.4)$ & $4117(30.6)$ \\
\hline \multicolumn{3}{|l|}{ Education level $^{b}$} \\
\hline Shorter than 9 years & $24(0.2)$ & $17(0.1)$ \\
\hline Elementary school & $333(2.6)$ & $241(1.8)$ \\
\hline High school & $3290(25.3)$ & $3112(23.1)$ \\
\hline University & $8784(67.4)$ & 9090 (67.6) \\
\hline \multicolumn{3}{|l|}{ Parity ${ }^{c}$} \\
\hline Primipara & 5942 (45.6) & $6305(46.9)$ \\
\hline Multipara & $7021(53.9)$ & $7105(52.8)$ \\
\hline Previous stillbirth & $66(0.5)$ & $38(0.3)$ \\
\hline $\begin{array}{l}\text { Tobacco user at registration } \\
\text { at the maternity } \text { clinic }^{c}\end{array}$ & $500(3.8)$ & $390(2.9)$ \\
\hline \multicolumn{3}{|l|}{ Civic status ${ }^{c}$} \\
\hline Cohabiting with becoming father & $12,211(93.7)$ & $12,458(92.6)$ \\
\hline Single & $141(1.1)$ & $208(1.5)$ \\
\hline Other family situation & $382(2.9)$ & $467(3.5)$ \\
\hline \multicolumn{3}{|l|}{ Body Mass Index ${ }^{d}$} \\
\hline$<18.5$ & $351(2.7)$ & $286(2.1)$ \\
\hline $18.5-24.9$ & 8289 (63.6) & $8481(63.0)$ \\
\hline $25.0-29.9$ & $2591(19.9)$ & $2874(21.4)$ \\
\hline $30.0-34.9$ & $855(6.6)$ & $888(6.6)$ \\
\hline$\geq 35.0$ & $354(2.7)$ & $308(2.3)$ \\
\hline Assisted reproduction $^{c}$ & $797(6.1)$ & $889(6.6)$ \\
\hline \multicolumn{3}{|l|}{ Maternal diseases } \\
\hline Diabetes mellitus & $17(0.1)$ & $16(0.1)$ \\
\hline Coronary heart disease & $209(1.6)$ & $229(1.7)$ \\
\hline Thrombosis & $110(0.8)$ & $125(0.9)$ \\
\hline Systemic lupus erythematosus (SLE) & $15(0.1)$ & $29(0.2)$ \\
\hline Psychiatric care & $2073(15.9)$ & $2208(16.4)$ \\
\hline Endocrine disease & $845(6.5)$ & $1007(7.5)$ \\
\hline Epilepsy & $62(0.5)$ & $75(0.6)$ \\
\hline Chronic hypertension & $51(0.4)$ & $79(0.6)$ \\
\hline Other disease & $1364(10.5)$ & $1408(10.5)$ \\
\hline $\begin{array}{l}\text { Medication or psychological } \\
\text { treatment for mental illness }\end{array}$ & $958(7.4)$ & $758(5.6)$ \\
\hline
\end{tabular}

${ }^{a}$ Mean: 32.2 vs. 32.6 (SE 0.04 vs. 0.04 ), Median: 32.0 vs. 32.4, Range 15.752.0 vs. $16.4-52.1$, Interquartile range $28.8-35.4$ vs. $29.3-35.8$

${ }^{b}$ Missing: Mindfetalness $n=598$ (4.6\%); Routine care $n=996(7.4 \%)$

cMissing: Mindfetalness $n=66(0.5 \%)$; Routine care $n=46(0.3 \%)$

${ }^{\mathrm{d}}$ Missing: Mindfetalness $n=589$ (4.5\%); Routine care $n=619$ (4.6\%)
To better understand the possible effects of such a strategy, we restricted the analysis to Swedish-born women, avoiding possible confounding or modifying effects by including women not born in Sweden. We found no indication that being aware of fetal movements causes harm. We believe that the debate that emerged after the AFFI RM-trial has distorted the concept of maternal awareness. The trial had two interventions presented as one; one aimed towards health-care professionals and one towards women, of increasing awareness of fetal movements [3]. These interventions were performed at the same time. Moreover, although not statistically significant, it is important to note that the two interventions together resulted in a stillbirth rate of 4.06 per thousand births, compared to 4.40 in standard care. Further, concerning the AFFIRM trial, it has been argued that almost $40 \%$ of the maternity clinics had low compliance to the intervention guidelines. Our study comprised one intervention only; midwives in half of the maternity clinics promoted Mindfetalness as a means of increasing awareness of fetal movements. We found a decreased rate of caesarean section and labor induction. We have no indication that clinical practice in managing women with decreased fetal movements was any different in the two groups we compared. The obstetricians did not know which maternity clinics were randomized to our intervention with Mindfetalness. We believe the way forward differs to what Walker and Thornton [2] and Gidlöf [14] suggest. Taken together, the results of the AFFIRM study, our study, and the one conducted by Tveit and co-workers [15], do not support concerns that increased awareness of fetal movements causes harm. Additionally, in a recent systematic review and meta-analysis investigating the effect of fetal movement counting in perinatal mortality and obstetric outcomes, an $8 \%$ reduction in perinatal mortality was seen in the fetal movement counting group (CI 0.85-1.00) [16]. The rate of labor induction and cesarean section was somewhat higher in the counting group. The participants of one study contributed to $82 \%$ of the total number of participants across all studies included in the review, which the authors regarded as a limitation. A comparison of the Mindfetalness-trial with the results of this review is difficult, as our study design and the concept "awareness of fetal movements" differs from those of the studies included in the article by Belussi et al. [16].

We found that less women had small-for-gestational-age infants in the Mindfetalness group. One explanation for this observation might be correlated to the instructions for practicing Mindfetalness. In the leaflet, the women were instructed to observe fetal movements on a daily basis, lying down on their side, to optimize blood flow to the placenta. Women who read the leaflet might have therefore adopted this position when going to sleep, rather than a supine position. Researchers have found an association between 
Table 2 Obstetric outcomes among women born in Sweden with birth from gestation 32+ 0; 13,029 women registered at a maternity clinic randomized to Mindfetalness and 13,456 women registered at a maternity clinic randomized to routine care

\begin{tabular}{|c|c|c|c|c|}
\hline Outcome & $\begin{array}{l}\text { Mindfetalness } \\
n(\%)\end{array}$ & $\begin{array}{l}\text { Routine care } \\
n(\%)\end{array}$ & $\begin{array}{l}\text { Rate Ratio } \\
(95 \% \mathrm{Cl})\end{array}$ & $p$-value \\
\hline Induction of labor & $2500(19.2)$ & $2729(20.3)$ & $0.95(0.90-0.99)$ & 0.03 \\
\hline Cesarean section (total) & $2394(18.4)$ & $2692(20.0)$ & $0.92(0.87-0.97)$ & $<0.001$ \\
\hline Pre-labor & $1297(10.0)$ & $1470(10.9)$ & $0.91(0.85-0.98)$ & 0.01 \\
\hline In labor & $1097(8.4)$ & $1222(9.1)$ & $0.93(0.86-1.00)$ & 0.06 \\
\hline Spontaneous start of labor & $9238(70.9)$ & $9263(68.8)$ & $1.03(1.01-1.05)$ & $<0.001$ \\
\hline Preterm delivery $(<37+0)$ & $483(3.7)$ & 479 (3.6) & $1.04(0.92-1.18)$ & 0.53 \\
\hline Birth gestation $>41+6$ & $687(5.3)$ & $804(6.0)$ & $0.88(0.80-0.97)$ & 0.01 \\
\hline Apgar Score $<7$ at $5 \mathrm{~min}^{\mathrm{a}, \mathrm{d}}$ & $127(1.0)$ & $128(1.0)$ & $1.02(0.80-1.31)$ & 0.85 \\
\hline Apgar Score $<4$ at $5 \min ^{\mathrm{a}, \mathrm{d}}$ & $48(0.4)$ & $39(0.3)$ & $1.27(0.83-1.94)$ & 0.28 \\
\hline Birthweight $\leq 10$ th centile ${ }^{b, e}$ & $1107(8.5)$ & $1253(9.3)$ & $0.91(0.85-0.99)$ & 0.02 \\
\hline Birthweight $<2 S D^{c, e}$ & $315(2.4)$ & $360(2.7)$ & $0.90(0.78-1.05)$ & 0.19 \\
\hline Admitted to NICU & $832(6.4)$ & $914(6.8)$ & $0.94(0.86-1.03)$ & 0.19 \\
\hline Death within 27 days after birth & $2(0.0)$ & $2(0.0)$ & $1.02(0.14-7.26)$ & 1.00 \\
\hline
\end{tabular}

${ }^{a}$ Number of stillbirths: Mindfetalness $n=17(0.1 \%)$; Routine care $n=14(0.1 \%)$

${ }^{b}$ International definition of Small for Gestational Age (SGA) $\leq 10$ th centile for the gestational age

'Swedish definition of Small for Gestational Age (SGA) <2SD from the national reference mean

${ }^{d}$ Missing 46: Mindfetalness $20(0.2 \%)$, Routine care $26(0.2 \%)$

'Missing 23: Mindfetalness 11 (0.1\%), Routine care $12(0.1 \%)$

NICU Neonatal intensive care unit

supine sleep position and reduced birthweight and even stillbirth $[17,18]$.

\section{Strengths and limitations}

Our effect measures are somewhat diluted because not all of the women randomly allocated to Mindfetalness practiced it. From the knowledge obtained from the original Mindfetalness trial and its pilot study [12], we know that approximately $78 \%$ of the leaflets were distributed (all languages included) and about $75 \%$ of the women practiced the method. Moreover, possible contamination between the two groups studied is an issue. Pregnant women change maternity clinics during pregnancy, and midwives change their workplace. Additionally, the website

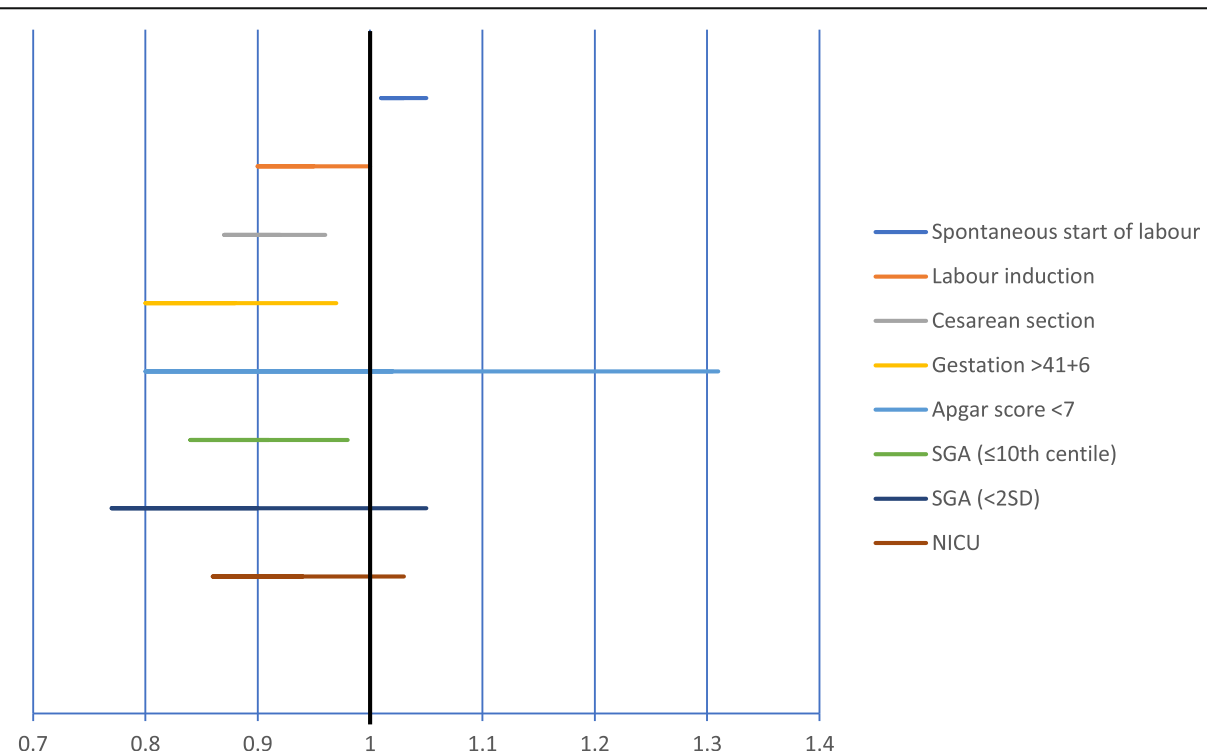

Fig. 1 Risk ratio for obstetric outcomes from 32 weeks' gestation among women born in Sweden randomized to Mindfetalness compared to routine care 
Table 3 Obstetric and birth outcomes women born in Sweden with birth from 32 weeks' gestation; 13,029 women registered at a maternity clinic randomized to Mindfetalness and 13,456 women registered at a maternity clinic randomized to routine care. Obstetric outcomes adjusted for age, educational level, body mass index, previous stillbirth, tobacco use at registration and treatment for mental illness

\begin{tabular}{|c|c|c|c|c|c|}
\hline Outcome & $\begin{array}{l}\text { Mindfetalness } \\
n(\%)\end{array}$ & $\begin{array}{l}\text { Routine care } \\
n(\%)\end{array}$ & $\mathbf{R R}$ & $p$-value & $\mathrm{Cl}$ \\
\hline Induction of labor & $2500(19.2)$ & $2729(20.3)$ & 0.95 & 0.03 & $0.90-0.99$ \\
\hline \multicolumn{6}{|l|}{ Adjusted for: } \\
\hline Age & & & 0.95 & 0.03 & $0.90-1.00$ \\
\hline Educational level & & & 0.93 & 0.006 & $0.89-0.98$ \\
\hline Body mass index & & & 0.95 & 0.04 & $0.90-1.00$ \\
\hline Previous stillbirth & & & 0.94 & 0.02 & $0.90-0.99$ \\
\hline Tobacco use at registration & & & 0.94 & 0.02 & $0.90-0.99$ \\
\hline Treatment for mental illness & & & 0.94 & 0.02 & $0.90-0.99$ \\
\hline Cesarean section & $2394(18.4)$ & $2692(20.0)$ & 0.92 & $<0.001$ & $0.87-0.97$ \\
\hline \multicolumn{6}{|l|}{ Adjusted for: } \\
\hline Age & & & 0.93 & 0.006 & $0.89-0.98$ \\
\hline Educational level & & & 0.92 & 0.002 & $0.88-0.97$ \\
\hline Body mass index & & & 0.92 & $<0.001$ & $0.87-0.96$ \\
\hline Previous stillbirth & & & 0.92 & $<0.001$ & $0.87-0.96$ \\
\hline Tobacco use at registration & & & 0.92 & $<0.001$ & $0.87-0.96$ \\
\hline Treatment for mental illness & & & 0.92 & $<0.001$ & $0.87-0.96$ \\
\hline Cesarean pre-labor & $1297(10.0)$ & $1470(10.9)$ & 0.91 & 0.01 & $0.85-0.98$ \\
\hline \multicolumn{6}{|l|}{ Adjusted for: } \\
\hline Age & & & 0.94 & 0.06 & $0.87-1.00$ \\
\hline Educational level & & & 0.92 & 0.02 & $0.85-0.98$ \\
\hline Body mass index & & & 0.91 & 0.01 & $0.85-0.98$ \\
\hline Previous stillbirth & & & 0.91 & 0.008 & $0.85-0.98$ \\
\hline Tobacco use at registration & & & 0.91 & 0.009 & $0.85-0.98$ \\
\hline Treatment for mental illness & & & 0.91 & 0.007 & $0.85-0.97$ \\
\hline Cesarean in labor & $1097(8.4)$ & $1222(9.1)$ & 0.93 & 0.06 & $0.86-1.00$ \\
\hline \multicolumn{6}{|l|}{ Adjusted for: } \\
\hline Age & & & 0.93 & 0.07 & $0.86-1.01$ \\
\hline Educational level & & & 0.93 & 0.08 & $0.86-1.01$ \\
\hline Body mass index & & & 0.92 & 0.04 & $0.85-1.00$ \\
\hline Previous stillbirth & & & 0.93 & 0.05 & $0.86-1.00$ \\
\hline Tobacco use at registration & & & 0.92 & 0.05 & $0.85-1.00$ \\
\hline Treatment for mental illness & & & 0.92 & 0.05 & $0.85-1.00$ \\
\hline Spontaneous start of labor & $9238(70.9)$ & $9263(68.8)$ & 1.03 & $<0.001$ & $1.01-1.05$ \\
\hline \multicolumn{6}{|l|}{ Adjusted for: } \\
\hline Age & & & 1.02 & 0.002 & $1.01-1.04$ \\
\hline Educational level & & & 1.03 & $<0.001$ & $1.02-1.05$ \\
\hline Body mass index & & & 1.03 & $<0.001$ & $1.01-1.04$ \\
\hline Previous stillbirth & & & 1.03 & $<0.001$ & $1.02-1.05$ \\
\hline Tobbacco use at registration & & & 1.03 & $<0.001$ & $1.01-1.05$ \\
\hline Treatment for mental illness & & & 1.03 & $<0.001$ & $1.01-1.05$ \\
\hline
\end{tabular}


Table 3 Obstetric and birth outcomes women born in Sweden with birth from 32 weeks' gestation; 13,029 women registered at a maternity clinic randomized to Mindfetalness and 13,456 women registered at a maternity clinic randomized to routine care. Obstetric outcomes adjusted for age, educational level, body mass index, previous stillbirth, tobacco use at registration and treatment for mental illness (Continued)

\begin{tabular}{|c|c|c|c|c|c|}
\hline Outcome & $\begin{array}{l}\text { Mindfetalness } \\
n(\%)\end{array}$ & $\begin{array}{l}\text { Routine care } \\
n(\%)\end{array}$ & RR & $p$-value & $\mathrm{Cl}$ \\
\hline Preterm delivery & $483(3.7)$ & 479 (3.6) & 1.04 & 0.52 & $0.92-1.18$ \\
\hline \multicolumn{6}{|l|}{ Adjusted for: } \\
\hline Age at birth & & & 1.04 & 0.55 & $0.92-1.18$ \\
\hline Educational level & & & 1.04 & 0.55 & $0.91-1.18$ \\
\hline Body mass index & & & 1.05 & 0.44 & $0.93-1.20$ \\
\hline Previous stillbirth & & & 1.04 & 0.54 & $0.92-1.18$ \\
\hline Tobacco user at registration & & & 1.04 & 0.55 & $0.92-1.18$ \\
\hline Treatment for Mental illness & & & 1.04 & 0.55 & $0.92-1.18$ \\
\hline Gestation > $41+6$ & $687(5.3)$ & $804(6.0)$ & 0.88 & 0.01 & $0.80-0.97$ \\
\hline \multicolumn{6}{|l|}{ Adjusted for: } \\
\hline Age at birth & & & 0.88 & 0.01 & $0.80-0.97$ \\
\hline Educational level & & & 0.88 & 0.02 & $0.80-0.98$ \\
\hline Body mass index & & & 0.88 & 0.02 & $0.80-0.98$ \\
\hline Previous stillbirth & & & NA & NA & NA \\
\hline Tobacco user at registration & & & 0.88 & 0.01 & $0.80-0.97$ \\
\hline Treatment for Mental illness & & & 0.89 & 0.02 & $0.81-0.98$ \\
\hline Apgar score less than 7 at $5 \mathrm{~min}^{\mathrm{a}}$ & $127(1.0)$ & $128(1.0)$ & 1.02 & 0.85 & $0.80-1.31$ \\
\hline \multicolumn{6}{|l|}{ Adjusted for: } \\
\hline Age at birth & & & 1.02 & 0.88 & $0.80-1.30$ \\
\hline Educational level & & & 1.01 & 0.93 & $0.78-1.30$ \\
\hline Body mass index & & & 0.99 & 0.96 & $0.77-1.27$ \\
\hline Previous stillbirth & & & 1.02 & 0.86 & $0.80-1.31$ \\
\hline Tobacco user at registration & & & 1.02 & 0.86 & $0.80-1.31$ \\
\hline Treatment for Mental illness & & & 1.00 & 0.99 & $0.78-1.28$ \\
\hline Apgar score less than 4 at $5 \mathrm{~min}^{\mathrm{a}}$ & $48(0.4)$ & $39(0.3)$ & 1.27 & 0.26 & $0.83-1.95$ \\
\hline \multicolumn{6}{|l|}{ Adjusted for: } \\
\hline Age at birth & & & 1.27 & 0.27 & $0.83-1.94$ \\
\hline Educational level & & & 1.26 & 0.30 & $0.81-1.98$ \\
\hline Body mass index & & & 1.31 & 0.21 & $0.86-2.01$ \\
\hline Previous stillbirth & & & 1.27 & 0.27 & $0.83-1.94$ \\
\hline Tobacco user at registration & & & 1.27 & 0.26 & $0.84-1.95$ \\
\hline Treatment for Mental illness & & & 1.25 & 0.29 & $0.82-1.92$ \\
\hline Birthweight $\leq 10$ th centile & $1107(8.5)$ & $1253(9.3)$ & 0.91 & 0.02 & $0.84-0.98$ \\
\hline \multicolumn{6}{|l|}{ Adjusted for: } \\
\hline Age at birth & & & 0.91 & 0.01 & $0.84-0.98$ \\
\hline Educational level & & & 0.90 & 0.01 & $0.83-0.98$ \\
\hline Body mass index & & & 0.90 & 0.01 & $0.84-0.98$ \\
\hline Previous stillbirth & & & 0.91 & 0.02 & $0.84-0.98$ \\
\hline Tobacco user at registration & & & 0.91 & 0.01 & $0.84-0.98$ \\
\hline Treatment for Mental illness & & & 0.91 & 0.02 & $0.84-0.98$ \\
\hline
\end{tabular}


Table 3 Obstetric and birth outcomes women born in Sweden with birth from 32 weeks' gestation; 13,029 women registered at a maternity clinic randomized to Mindfetalness and 13,456 women registered at a maternity clinic randomized to routine care. Obstetric outcomes adjusted for age, educational level, body mass index, previous stillbirth, tobacco use at registration and treatment for mental illness (Continued)

\begin{tabular}{|c|c|c|c|c|c|}
\hline Outcome & $\begin{array}{l}\text { Mindfetalness } \\
n(\%)\end{array}$ & $\begin{array}{l}\text { Routine care } \\
n(\%)\end{array}$ & RR & $p$-value & $\mathrm{Cl}$ \\
\hline Birthweight $<2 S D^{b^{* * *}}$ & $315(2.4)$ & $360(2.7)$ & 0.90 & 0.18 & $0.78-1.05$ \\
\hline \multicolumn{6}{|l|}{ Adjusted for: } \\
\hline Age at birth & & & 0.90 & 0.16 & $0.77-1.04$ \\
\hline Educational level & & & 0.91 & 0.26 & $0.78-1.07$ \\
\hline Body mass index & & & 0.89 & 0.14 & $0.77-1.04$ \\
\hline Previous stillbirth & & & 0.90 & 0.19 & $0.78-1.05$ \\
\hline Tobacco user at registration & & & 0.90 & 0.17 & $0.77-1.04$ \\
\hline Treatment for Mental illness & & & 0.90 & 0.19 & $0.78-1.05$ \\
\hline Transfer to NICU & $832(6.4)$ & $914(6.8)$ & 0.94 & 0.18 & $0.86-1.03$ \\
\hline \multicolumn{6}{|l|}{ Adjusted for: } \\
\hline Age at birth & & & 0.94 & 0.19 & $0.86-1.03$ \\
\hline Educational level & & & 0.95 & 0.24 & $0.86-1.04$ \\
\hline Body mass index & & & 0.95 & 0.28 & $0.87-1.04$ \\
\hline Previous stillbirth & & & 0.94 & 0.18 & $0.86-1.03$ \\
\hline Tobacco user at registration & & & 0.94 & 0.17 & $0.86-1.03$ \\
\hline Treatment for Mental illness & & & 0.93 & 0.15 & $0.85-1.02$ \\
\hline Death within 27 days after birth & $2(0.0)$ & $2(0.0)$ & 1.03 & 0.97 & $0.12-8.61$ \\
\hline \multicolumn{6}{|l|}{ Adjusted for: } \\
\hline Age at birth & & & 1.07 & 0.94 & $0.13-8.96$ \\
\hline Educational level & & & 1.01 & 0.99 & $0.12-8.43$ \\
\hline Body mass index & & & 1.07 & 0.95 & $0.13-8.88$ \\
\hline Previous stillbirth & & & NA & NA & NA \\
\hline Tobacco user at registration & & & NA & NA & NA \\
\hline Treatment for Mental illness & & & NA & NA & NA \\
\hline Contacting healthcare due to DFM & $1011(7.8)$ & $584(4.3)$ & 1.79 & $<0.001$ & $1.62-1.97$ \\
\hline \multicolumn{6}{|l|}{ Adjusted for: } \\
\hline Age at birth & & & 1.77 & $<0.001$ & $1.60-1.95$ \\
\hline Educational level & & & 1.83 & $<0.001$ & $1.65-2.03$ \\
\hline Body mass index & & & 1.81 & $<0.001$ & $1.63-2.00$ \\
\hline Previous stillbirth & & & 1.79 & $<0.001$ & $1.62-1.98$ \\
\hline Tobacco user at registration & & & 1.79 & $<0.001$ & $1.62-1.97$ \\
\hline Treatment for Mental illness & & & 1.79 & $<0.001$ & $1.62-1.98$ \\
\hline
\end{tabular}

${ }^{a}$ Data are missing for 46 women (20 in Mindfetalness group and 26 in Routine care group)

bata are missing for 23 women (11 in Mindfetalness group and 12 in Routine care group)

*Number of stillbirths (Apgar $=0$ ) Mindfetalness $n=17(0.1 \%)$; Routine care $n=14(0.1 \%)$

**International definition of Small for Gestational Age (SGA) $\leq 10$ th centile for the gestational age

***Swedish definition of Small for Gestational Age (SGA) <2SD from the national reference mean

NICU Neonatal intensive care unit

was open for anyone to access, and media highlighted Mindfetalness during the study period. Further, participating in research about fetal movements may have had a potential effect on the midwives' behavior, both in the intervention and the routine care arm $[19,20]$. This type of misclassification may have diluted the results further, and the measured differences will in fact be greater in reality. The differences between the groups remain statistically significant, even after adjustment for confounders, and this strengthens the results, although is it possible that we have 
not identified all factors that could have affected the results. In moving forward, we may need to find essential components of the methods used to promote awareness of fetal movements. That may give us an understanding of the discrepancies between the varying results in different published studies. Perhaps the beneficial effects we have had are due to the fact that Mindfetalness (focusing on the strength, character and frequency of the movements but not count each movement) was a helpful tool for the women to get to know their unborn baby's movement pattern and to trust their intuition. We believe all evidence we have support that when women are aware of fetal movement, pregnancy outcome improves.

\section{Conclusion}

Our intervention increased the percentage of women seeking obstetric care for decreased fetal movements. If women with decreased fetal movements are more likely to seek care earlier, new opportunities emerge. Our data clearly showed no harm by increasing maternal awareness of fetal movements, on the contrary, we saw benefits. We may still have a lot to learn about how to help a woman improve her knowledge about her unborn baby's movement pattern and how a fetal-movement history can be translated to an even better pregnancy outcome than exists today.

\section{Supplementary information}

Supplementary information accompanies this paper at https://doi.org/10 1186/s12884-020-03268-1.

\section{Additional file 1}

\section{Abbreviations}

NICU: Neonatal intensive care unit; SGA: Small for gestational age

\section{Acknowledgements}

We would like to thank the midwives participating in the intervention and the pregnant women who received the information. Also, thanks to The Swedish Pregnancy Register. A special thanks to The Swedish Research Council for funding this study.

\section{Authors' contributions}

IR designed the study and were together with AA responsible for the methodology. AA were project administrator. AA and VS performed the analyses and AA wrote the first draft. All authors (IR, HL, VS and AA) were responsible and involved in writing and validation. IR is the PI for the study and received funding for the study. All authors read and approved the final manuscript.

\section{Funding}

The Swedish Research Council funded this study. Open Access funding provided by Sophiahemmet University College $(\mathrm{SHH})$

\section{Availability of data and materials}

The Ethics committee prohibit data to be publicly available due to confidential information. However, the data will be shared after an approval from the Regional Ethics committee in Stockholm, Sweden (https://etikprovningsmyndigheten.se/).

\section{Ethics approval and consent to participate}

The study was approved by The Regional Ethics committee in Stockholm, Sweden (Dnr 2015/2105-31/1), 13 January 2016. The women got informed that it was voluntary for them to accept information and practice the method. At registration in maternity clinic, the women gave written consent that their data in The Swedish Pregnancy Register can be used in research. Regarding consent to participate in research for underage study participants, from the age of 15, the authors refer to Swedish legislation (Law 2003: 460).

Consent for publication

Not applicable.

\section{Competing interests}

The authors declare that they have no competing interests and there are not any financial competing interests.

\section{Author details}

${ }^{1}$ Sophiahemmet University, Stockholm, Sweden. ${ }^{2}$ Department of Women and Children's Health, Karolinska Institutet, Stockholm, Sweden. ${ }^{3}$ Institute of Clinical Sciences, Sahlgrenska Academy, University of Gothenburg, Gothenburg, Sweden.

Received: 11 June 2020 Accepted: 18 September 2020

Published online: 01 October 2020

\section{References}

1. Flenady V, Ellwood D, Bradford B, Coory M, Middleton P, Gardener G, et al. Beyond the headlines: fetal movement awareness is an important stillbirth prevention strategy. Women Birth. 2019;32(1):1-2 PubMed PMID: 30563769. Epub 2018/12/20. Eng.

2. Walker KF, Thornton JG. Encouraging awareness of fetal movements is harmful. Lancet. 2018;392(10158):1601-2 PubMed PMID: 30269875. Epub 2018/10/03. Eng.

3. Norman JE, Heazell AEP, Rodriguez A, Weir CJ, Stock SJE, Calderwood CJ, et al. Awareness of fetal movements and care package to reduce fetal mortality (AFFIRM): a stepped wedge, cluster-randomised trial. Lancet. 2018, 392:1629 PubMed PMID: 30269876. Pubmed Central PMCID: PMC6215771. Epub 2018/10/03. Eng.

4. Vårdgivarguiden. Behandlingsstöd barnmorskor [cited 2020 0407]. Available from: http://www.vardgivarguiden.se/behandlingsstod/ barnmorskemottagning/.

5. Graviditetsregistret. Årsrapport 2017

6. Socialstyrelsen. Dödfödda barn - En inventering och förslag på åtgärde 2018 [cited 2019 01-28]. Available from: https://www.socialstyrelsen.se/ publikationer2018/2018-12-36/Sidor/default.aspx

7. Akselsson A, Lindgren H, Georgsson S, Pettersson K, Steineck G, Skokic V, et al. Mindfetalness to increase women's awareness of fetal movements and pregnancy outcomes: a cluster-randomised controlled trial including 39865 women. BJOG. 2020;127:829 PubMed PMID: 31971325. Epub 2020/01/24. Eng.

8. Radestad I, Akselsson A, Georgsson S, Lindgren H, Pettersson K, Steineck G. Rationale, study protocol and the cluster randomization process in a controlled trial including 40,000 women investigating the effects of mindfetalness. Sexual Reprod Healthcare. 2016;10:56-61 PubMed PMID: 27938874. Epub 2016/12/13. Eng.

9. Socialstyrelsen. Minskade fosterrörelser - rekommendationer om information, råd och en inledande bedömning - Kunskapsstöd med nationella rekommendationer 2016 [cited 2020 0407]. Available from: http://www.socialstyrelsen.se/publikationer2016/2016-10-9.

10. AB liG. ICD internetmedicin 2018 [cited 2018 December]. Available from: http://icd.internetmedicin.se/.

11. Graviditetsregistret. Graviditetsregistret 2018 [cited 2018 August 27] Available from: https://www.medscinet.com/gr/engelska.aspx.

12. Akselsson A, Georgsson S, Lindgren H, Pettersson K, Radestad I. Women's attitudes, experiences and compliance concerning the use of Mindfetalnessa method for systematic observation of fetal movements in late pregnancy. BMC Pregnancy Childbirth. 2017;17(1):359 PubMed PMID: 29037234 Pubmed Central PMCID: PMC5644086. Epub 2017/10/19. Eng.

13. Malm MC, Radestad I, Rubertsson C, Hildingsson I, Lindgren H. Women's experiences of two different self-assessment methods for monitoring fetal movements in full-term pregnancy--a crossover trial. BMC Pregnancy 
Childbirth. 2014;14:349 PubMed PMID: 25288075. Pubmed Central PMCID: PMC4286931. Epub 2014/10/08. Eng.

14. Gidlof $\mathrm{S}$. When will we stop encouraging awareness of fetal movements? Acta Obstet Gynecol Scand. 2019;98(2):137-8 PubMed PMID: 30681736. Epub 2019/01/27. Eng

15. Tveit JV, Saastad E, Stray-Pedersen B, Bordahl PE, Flenady V, Fretts R, et al. Reduction of late stillbirth with the introduction of fetal movement information and guidelines - a clinical quality improvement. BMC Pregnancy Childbirth. 2009;9:32 PubMed PMID: 19624847. Pubmed Central PMCID: PMC2734741. Epub 2009/07/25. Eng.

16. Bellussi F, Po G, Livi A, Saccone G, De Vivo V, Oliver EA, et al. Fetal movement counting and perinatal mortality: a systematic review and metaanalysis. Obstet Gynecol. 2020;135(2):453-62 PubMed PMID: 31923063. Epub 2020/01/11. Eng.

17. Anderson NH, Gordon A, Li M, Cronin RS, Thompson JMD, Raynes-Greenow $\mathrm{CH}$, et al. Association of Supine Going-to-Sleep Position in late pregnancy with reduced birth weight: a secondary analysis of an individual participant data meta-analysis. JAMA Netw Open. 2019;2(10):e1912614 PubMed PMID: 31577362. Pubmed Central PMCID: PMC6777255. Epub 2019/10/03. Eng.

18. Heazell A, Li M, Budd J, Thompson J, Stacey T, Cronin RS, et al. Association between maternal sleep practices and late stillbirth - findings from a stillbirth case-control study. BJOG. 2018;125(2):254-62 PubMed PMID: 29152887. Pubmed Central PMCID: PMC5765411. Epub 2017/11/21. Eng.

19. McCambridge J, Witton J, Elbourne DR. Systematic review of the Hawthorne effect: new concepts are needed to study research participation effects. J Clin Epidemiol. 2014;67(3):267-77 PubMed PMID: 24275499. Pubmed Central PMCID: PMC3969247. Epub 2013/11/28. Eng.

20. Parsons H. What happened at Hawthorne? Science. 1974;183(4128):922-32 PubMed PMID: 1974-26500-001. Eng.

\section{Publisher's Note}

Springer Nature remains neutral with regard to jurisdictional claims in published maps and institutional affiliations.

Ready to submit your research? Choose BMC and benefit from:

- fast, convenient online submission

- thorough peer review by experienced researchers in your field

- rapid publication on acceptance

- support for research data, including large and complex data types

- gold Open Access which fosters wider collaboration and increased citations

- maximum visibility for your research: over $100 \mathrm{M}$ website views per year

At $\mathrm{BMC}$, research is always in progress.

Learn more biomedcentral.com/submissions 